\title{
INFLUENCE OF CROWN SHAPE ON ROOT COVERAGE THERAPY
}

\author{
Maria Fernanda Santos PERES ${ }^{1}$, Érica Del Peloso RIBEIRO ${ }^{2}$, Sandro BITTENCOURT ${ }^{3}$, Enilson Antônio SALLUM ${ }^{4}$, \\ Antônio Wilson SALLUM ${ }^{4}$, Francisco Humberto NOCITI-JÚNIOR ${ }^{4}$, Márcio Zaffalon CASATI ${ }^{5}$
}

\author{
1- DDS, MS Student, Department of Periodontics, Piracicaba Dental School, State University of Campinas, Piracicaba, SP, Brazil. \\ 2- DDS, MSc, PhD, Department of Periodontics, Piracicaba Dental School, State University of Campinas, Piracicaba, SP, Brazil. \\ 3- DDS, MSc, PhD, Department of Periodontics, Piracicaba Dental School, State University of Campinas, Piracicaba, SP, Brazil. \\ 4- DDS, MSc, PhD, Professor, Department of Periodontics, Piracicaba Dental School, State University of Campinas, Piracicaba, SP, Brazil. \\ 5- DDS, MSc, PhD, Assistant Professor, Department of Periodontics, Piracicaba Dental School, State University of Campinas, Piracicaba, SP, Brazil.
}

Corresponding address: Faculdade de Odontologia de Piracicaba/UNICAMP - Av. Limeira, 901 - 13414-903 - Caixa Postal 52 - Piracicaba, SP, Brasil

Phone: +55-19-21065301- Fax: +55-19-21065301 - e-mail: ma_fe_nanda@fop.unicamp.br - e-mail: casati@fop.unicamp.br

Received: June 2, 2008 - Accepted: October 10, 2008

\begin{abstract}
$O$

bjectives: The aim of this study was to evaluate the influence of the crown shape on the outcomes of root coverage procedures. Material and methods: Eighty patients with Miller class I gingival recessions in maxillary canines or premolars were selected. The recession areas were treated using the subepithelial connective tissue grafting. The following clinical parameters were analyzed: crown length (CL) and width (CW), recession height and width, probing depth, clinical attachment level, width and thickness of the keratinized tissue and percentage of root coverage achieved. These measurements were recorded at baseline and 6 months after the surgical procedure. The CW/CL ratio was calculated for each tooth and the median obtained (0.83). Patients were then ranked into two groups, according to the shape of the tooth with gingival recession: Group A - square crown shape (CW/CL values above 0.83) and Group B - long and narrow crown shape (CW/CL values below 0.83). Results: No statistically significant differences ( $>>0.05$ ) were found between groups in any of the clinical parameters at baseline. After 6 months, both groups presented improved clinical outcomes for all parameters analyzed compared to baseline $(\mathrm{p}>0.05)$. The mean percentages and standard deviations of root coverage achieved in Group A and Group B was 91.37 (16.75) and 85.49 (23.55), respectively ( $>0.05)$. Conclusions: Crown shape did not influence the root coverage obtained with the subepithelial connective tissue graft technique.
\end{abstract}

Key words: Root coverage. Crown shape. Connective tissue graft.

\section{INTRODUCTION}

Gingival recession is defined as the location of marginal tissue apical to the cementoenamel junction ${ }^{2}$ due to attachment loss followed by alveolar bone crest resorption and cementum necrosis, as a consequence of inflammatory conditions on the gingival connective tissue ${ }^{3}$. These lesions are common features in populations with poor oral hygiene and traumatic toothbrushing ${ }^{10,11}$.

The indications for surgical coverage of exposed roots are traditionally root hypersensitivity, esthetic demands and higher risk of root caries ${ }^{5}$. Systematic reviews ${ }^{5,13,16}$ revealed that a variety of surgical techniques result in statistically significant coverage of gingival recessions. Results have been shown to range from $64.6 \%{ }^{18}$ to $95.6 \%{ }^{18}$ of complete root coverage with the subepithelial connective tissue grafting. On the other hand, some studies and systematic reviews $s^{5,13,16}$ have also yielded a marked variability for percentage of root coverage and percentage of subjects with complete coverage both between and within surgical techniques.

The clinical outcomes achieved with root coverage procedures can vary according to patients' characteristics and surgical technique factors, but may also be related to morphological periodontal characteristics of the periodontium ${ }^{18}$. It has been clinically observed that gingival height, thickness and contours, probing depth and clinical attachment level vary considerably in a population, characterizing different periodontal phenotypes.

Olsson and Lindhe ${ }^{14}$ studied the periodontal characteristics of individuals with varying shapes of the maxillary central incisors and described the existence of two crown types: one presenting a long and narrow shape and the other displaying a short and wide shape. These authors reported that subjects with a long and narrow crown shape experienced more gingival recession than those who had a short and wide crown shape. However, those authors did not evaluate the influence of crown shape on root coverage 
therapy.

Based on the correlation between crown shape and the morphological periodontal characteristics, Müller and Eger ${ }^{11,12}$ described three different periodontal phenotypes (A, B and C). The "A" phenotype presents "normal" or "medium" gingival thickness, keratinized tissue height and ratio of crown width to its length. The "B" phenotype presents higher keratinized gingival thickness and height, where the crown ratio is closer to 1 and the crown has a square shape. The "C" phenotype presents "normal" or "medium" gingival thickness, similar to phenotype "A", with a crown ratio even closer to 1 and teeth with a more square shape, but with a narrow keratinized gingival height. Those authors observed a higher prevalence of gingival recession in Group "A" than in Group " $C$ ". It was suggested that periodontal disease symptoms, such as gingival recession and higher probing depths, may vary in different periodontal phenotypes. Therefore, considering that the tooth and the periodontium are anatomically and physiologically related, morphological characteristics of the periodontium may be related to dental anatomy $y^{4,7-9,14,15,19,20}$ and the crown shape is one of the variables of periodontal phenotypes. As such, there is a possibility that crown shape is related to root coverage. However, little research-based data is available to support this hypothesis since only the association between dental anatomy and gingival recession incidence has been demonstrated. Thus, the aim of the present study was to correlate the crown shape to the root coverage obtained using the subepithelial connective tissue graft.

\section{MATERIAL AND METHODS}

\section{Study Population}

Subjects for this study were selected from patients referred for dental treatment to Piracicaba Dental School, State University of Campinas, Brazil. Patients were enrolled between March 2004 and July 2006. Only non-smoker periodontally and systemically healthy patients with no contraindications for periodontal surgery and who had not taken medications known to interfere with periodontal tissue health or healing were considered as eligible participants. The following inclusion criteria were used: (I) Miller Class I gingival recessions in maxillary canines or premolars, (II) probing depth $(\mathrm{PD})=3 \mathrm{~mm}$ without bleeding on probing, and (III) tooth vitality and absence of caries or restorations in the areas to be treated. The sample consisted of 80 patients who met all criteria to entry the study. An informed consent form was signed by each subject after a thorough explanation of the nature, risks and benefits of the clinical investigation and associated procedures. The consent form and experimental protocol were reviewed and approved by the institutional Research Ethics Committee.

\section{Initial Therapy}

The patients initially completed a plaque control program, including oral hygiene instructions (non-traumatic toothbrushing technique), scaling, root planing and crown polishing. Visible plaque index (VPI) and sulcus bleeding index (SBI) were used to assess gingival health conditions throughout the study.

\section{Clinical Parameters}

All measurements were recorded at baseline (28 days after the initial therapy) and 6 months after the surgical procedure by a blinded examiner (EDPR), and quantified with a caliper accurate to the nearest $0.01 \mathrm{~mm}$ (Absolute, Mitutoyo Sul Americana, Suzano, SP, Brazil). Measurements were made from the incisal border of the tooth to the cementoenamel junction (CEJ), to the mucogingival junction (MGJ), and to the gingival margin (GM) using an endodontic finger spreader attached to a rubber stopper. The identification of the MGJ was facilitated by staining the tissues with iodine solution. Recession height $(\mathrm{RH})$, the distance from the CEJ to the GM (calculated as GM - CEJ), and the width of keratinized tissue (WKT), the distance between the most apical point of GM, and MGJ (calculated as MGJ - GM), were assessed with these measurements. Recession width (RW) from one border of the recession to another, measured at the CEJ, and PD, determined as the distance from the GM to the bottom of the gingival sulcus, were measured using a periodontal probe with a rubber stopper. Clinical attachment level (CAL) was calculated as $\mathrm{RH}+\mathrm{PD}$.

Thickness of the keratinized tissue (TKT) was assessed $2 \mathrm{~mm}$ apical to the GM before surgery. In cases in which the patient had only $2 \mathrm{~mm}$ keratinized tissue to start with, TKT was measured slightly coronal to the MGJ. After removing the spreader carefully, penetration depth was measured with the caliper accurate to the nearest $0.01 \mathrm{~mm}$.

Crown length (CL), from the CEJ to the incisal border of the tooth, measured in its longer length, and crown width (CW) measured from mesial to distal in its larger width. These measurements were used to evaluate the influence of crown shape on the root coverage achieved ( $\mathrm{RC} \%)$.

\section{Group Classification}

The CW/CL ratio was calculated for each patient after determining CW and CL. The median of all CW/CL ratio values was calculated $(0.83)$ and the patients were then allocated into two groups. In Group A, the patients presented CW/CL values above 0.83 , and presented a square crown shape (Figure 1). In Group B, patients presented CW/CL values below 0.83 , and presented a long and narrow crown shape (Figure 2).

\section{Surgical Procedures}

All surgical procedures were performed by the same operator (SB) using the subepithelial connective tissue graft (SCTG) technique with an operative microscope. Before surgery, extra oral antisepsis was performed with a $2.0 \%$ chlorhexidine solution and intraoral antisepsis with $0.12 \%$ chlorhexidine rinse. The SCTG was performed, as described by Campos, et $\mathrm{al}^{6}$. (2006). 


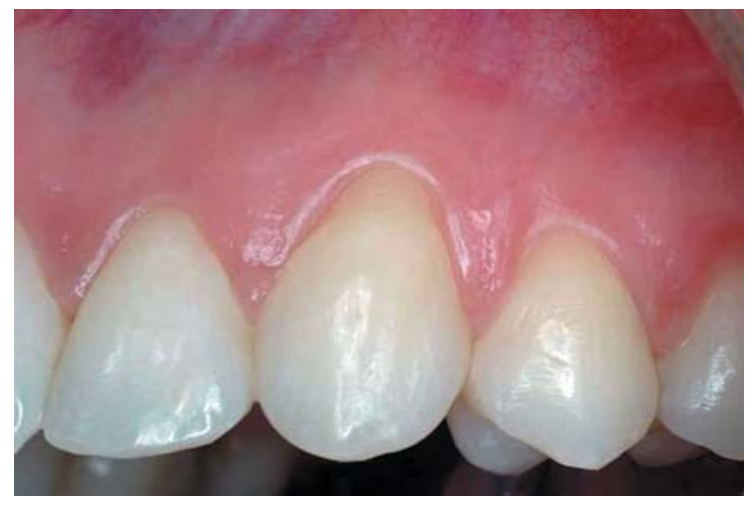

FIGURE 1- Group A, presenting a quadratic crown shape

\section{Post-Surgical Care}

Patients were instructed to take analgesic medication (500 mg of sodium dipyrone) if they experienced pain. Microsutures were removed after 7 days. All patients were instructed not to brush around the surgical sites within the first 30 days after surgery. During this period, chemical plaque control was prescribed $(0.12 \%$ chlorhexidine rinse, twice a day). After this period, gentle toothbrushing with soft-bristle toothbrush was permitted. The subjects were enrolled in a periodontal maintenance program composed of professional rubber/pumice prophylaxis and reinforcement of oral hygiene instructions, weekly for the first 4 weeks and then monthly until the end of the study period.

TABLE 1- Clinical parameters at baseline

\begin{tabular}{llll}
\hline & Group A & Group B & p value \\
\hline RH & $2.46(0.62)$ & $2.30(0.54)$ & $\mathrm{p}>0.05^{*}$ \\
RW & $3.86(0.61)$ & $3.76(0.70)$ & $\mathrm{p}>0.05^{*}$ \\
WKT & $2.88(1.22)$ & $2.64(1.10)$ & $\mathrm{p}>0.05^{*}$ \\
TKT & $0.90(0.19)$ & $0.95(0.21)$ & $\mathrm{p}>0.05^{*}$ \\
PD & $1.24(0.46)$ & $1.34(0.44)$ & $\mathrm{p}>0.05^{*}$ \\
CAL & $3.67(0.80)$ & $3.63(0.63)$ & $\mathrm{p}>0.05^{*}$ \\
\hline
\end{tabular}

*Student's t test. The values are expressed as mean (standard deviation).

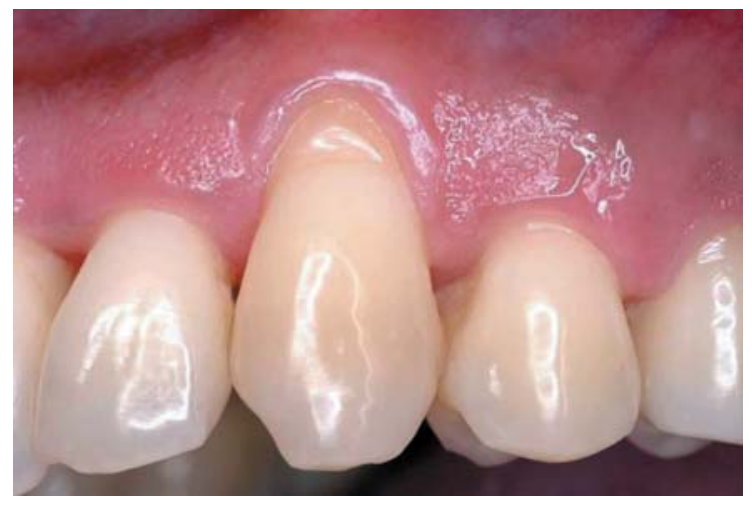

FIGURE 2- Group B, presenting a long and narrow crown shape

\section{Statistical Analysis}

The Mann Whitney test was performed to analyze RC\% achieved in Groups A and B. The Student's t-test was used to compare the variables RW, PD, CAL, TKT and WKT between the groups at baseline. Two-way ANOVA was used to compare $\mathrm{RH}$, before and 6 months after the surgical procedures. A significance level of 0.05 was set for all statistical analyses. All evaluations used the patient as the unit of measurement.

\section{RESULTS}

The mean age of the subjects was 33.2 years in Group A and 35.7 years in Group B. A total of 80 patients with 80 gingival recessions ( $n=40 /$ group) were evaluated. The clinical parameters RH, RW, PD, WKT, TKT and CAL were not statistically different ( $\mathrm{p}>0.05$ ) between Groups A and B at baseline. These values are shown in Table 1.

After six months, both groups experienced improvement in clinical outcomes for all analyzed parameters. The mean $\mathrm{RC} \%$ in Group A was 91.37 (16.76), and 85.49 (23.55) in Group B, without statistical difference between them (p>0.05) (Table 2).

Complete root coverage was accomplished in $70.0 \%$ (28 out of 40) of the treated cases in Group A and in 62.5\% (25 out of 40) in Group B. Six months after the surgical procedures, the mean RH values were 0.35 (0.55), and 0.22 $(0.48)$ in Groups A and B ( $>00.05)$, respectively.

TABLE 2- Root coverage (RC\%) achieved in Groups A and B

\begin{tabular}{lcccc}
\hline Group & Median & Minimum & Maximum & Mean (SD) \\
\hline A & $100.00 \mathrm{a}$ & 25.23 & 100.00 & $91.37(16.76)$ \\
B & $100.00 \mathrm{a}$ & 24.19 & 100.00 & $85.49(23.55)$ \\
\hline
\end{tabular}

Medians followed by the same letter indicate no statistically significant difference between the groups (Mann Whitney test; $p>0.05)$ 


\section{DISCUSSION}

The clinical outcomes achieved with root coverage procedures can be influenced by factors such as patients characteristics and surgical technique factors. Information lacks regarding the relationship between crown shape and the morphological characteristics of the periodontium ${ }^{4,12,15}$. Therefore, the present study investigated the influence of crown shape on the outcomes of root coverage procedures.

A previous study ${ }^{14}$ described the existence of two types of crowns maxillary central incisors: one displaying a long and narrow shape and the other presenting a short and wide shape. In the studied population, the long and narrow crown shape was associated with more gingival recession than the short and wide crown shape.

Muller and $\operatorname{Eger}^{12}$ (1997) found a relationship between crown shape and the morphological characteristics of the periodontium, and described not just two, but three gingival phenotypes and crown shapes $(\mathrm{A}, \mathrm{B} \text { and } \mathrm{C})^{12}$. Group $\mathrm{A}$ displayed a "normal" gingival thickness, with gingival width associated with a "normal" crown shape. Group B displayed a significantly thicker and wider gingival, associated with a "square crown shape", and Group C displayed a "normal" gingival thickness, but a narrow zone of keratinized tissue and an "even more square" crown shape. Those authors reported that the highest prevalence of gingival recession was observed in Group "A".

The previously mentioned studies supported the hypothesis that crown shape might be related to gingival recession ${ }^{4,12,15}$, but no data exist to demonstrate the influence of crown shape during the surgical treatment of gingival recession. In addition, to the best of our knowledge, no study has investigated the predictability and recession resolution using subepithelial connective tissue grafts in individuals with different crown shapes.

The present study failed to demonstrate a relationship between morphological characteristics of the periodontium, such as keratinized tissue width, gingival thickness and contour, probing depth and clinical attachment level and crown shape. For this investigation, patients were split into two groups (A and B), according to their crown shapes ${ }^{14}$. However, no significant differences were observed between groups in any of the clinical parameters at baseline (RW, $\mathrm{PD}, \mathrm{WKT}$ and CAL), which is in contrast with those of the previously mentioned studies ${ }^{12,14,15}$. This difference can be attributed either to the different methods used to measure clinical parameters or to the classification of the patients into groups, according to the crown shape. In the present study, in order to use a numerical parameter for classification, the median of the crown ratios of the study population $(0.83)$ was calculated and the patients were allocated into two groups based on this value.

With regard to the relationship between crown shape and root coverage, both groups experienced improved clinical outcomes in terms of root coverage after 6 months. The means and standard deviation for RC\% in Groups A and B were 85.27 (23.78) and 91.37 (16.75), respectively, without statistically significant difference. These results are in agreement with studies using various flap and graft techniques in controlled clinical trials ${ }^{1,4,9,17,21}$. More clinical studies are necessary to elucidate the factors that influence the results obtained with root coverage procedures.

\section{CONCLUSIONS}

Within the limitations of the present study, it was possible to demonstrate that the crown shape does not influence root coverage outcomes when using the subepithelial connective tissue graft technique.

\section{REFERENCES}

1- Aichelmann-Reidy ME, Yukna RA, Evans GH, Nasr HF, Mayer ET. Clinical evaluation of acellular allograft dermis for the treatment of human gingival recession. J Periodontol. 2001;72(8):998-1005.

2- American Academy of Periodontology. Glossary of periodontal terms. 4th ed. Chicago: American Academy of Periodontology; 2001.

3- Baker DL, Seymour GJ. The possible pathogenesis of gingival recession: a histological study of induced recession in the rat. J Clin Periodontol. 1976;3(4):208-19.

4- Bittencourt S, Ribeiro EDP, Sallum EA, Sallum AW, Nociti FH Jr, Casati MZ. Comparative 6-month clinical study of a semilunar coronally positioned flap and subepithelial connective tissue graft for the treatment of gingival recession. J Periodontol. 2006;77(2):174-81.

5- Bouchard P, Malet J, Borghetti A. Decision-making in aesthetics: root coverage revisited. Periodontol 2000. 2001;27:97-120.

6- Campos GV, Bittencourt S, Sallum AW, Nociti FH Jr, Sallum EA, Casati MZ. Achieving primary closure and enhancing aesthetics with periodontal microsurgery. Pract Proced Aesthet Dent. 2006;18(7):449-54.

7- Glickman I. Clinical periodontology. 4th ed. Philadelphia: WB.Saunders; 1972.

8- Grant DA, Stern IB, Listgarten MA. Periodontics. 6th ed. St Louis: CV Mosby; 1988.

9- Huang LH, Neiva RE, Wang HL. Factors affecting the outcomes of coronally advanced flap root coverage procedure. J Periodontol. 2005;76(10):1729-34.

10- Joshipura KJ, Kent RL, DePaola PF. Gingival recession: intra-oral distribution and associated factors. J Periodontol. 1994;65(9):864-71.

11- Löe H, Anerud A, Boysen H. The natural story of periodontal disease in man: prevalence, severity, and extent of gingival recession. J Periodontol. 1992;63(6):489-95.

12- Muller HP, Eger T. Gingival phenotypes in young male adults. J Clin Periodontol. 1997;24(1):65-71

13- Oates TW, Robinson M, Gunsolley JC. Surgical therapies for the treatment of gingival recessiona: a systematic review. Ann Periodontol. 2003;8(1):303-20.

14- Olsson M, Lindhe J. Periodontal characteristics in individuals with varying forms of the upper central incisor. J Clin Periodontol. $1991 ; 18(1): 78-82$. 
15- Olsson M, Lindhe J, Marinello CP. On the relationship between crown form and clinical features of the gingival in adolescents. J Clin Periodontol. 1993;20(8):570-7.

16- Roccuzzo M, Bunino M, Needleman I, Sanz M. Periodontal plastic surgery for treatment of localized gingival recessions: a systematic review. J Clin Periodontol. 2002;29(Suppl 3):178-94; discussion 195-6.

17- Rossetti PE, Marcantonio RAC, Rossa C Jr, Chaves ES, Goissis G, Marcantonio E Jr. Treatment of gingival recession: comparative study between subepithelial connective tissue graft and guided tissue regeneration. J Periodontol. 2000;71(9):1442-7.

18- Saletta D, Pini Prato G, Pagliaro U, Baldi C, Mauri M, Nieri M. Coronally advanced flap procedure: is the interdental papilla a prognostic factor for root coverage? J Periodontol. 2001;72(6):760-6.

19- Schluger S, Yuodelis RA, Page R. Periodontal disease. 1st ed. Philadelphia: Lea \& Febiger; 1977.

20- Seibert JS. Surgical management of osseous defects. In: Goldman HM, Cohen DW, editors. Periodontal therapy. 5th ed. Saint Louis: CV Mosby; 1977. p. 775-6.

21- Silva RC, Joly JC, Lima AFM, Tatakis DN. Root coverage using coronally positioned flap with or without a subepithelial connective tissue graft. J Periodontol. 2004;78(9):1702-7. 